\title{
The male bias of a generically-intended personal pronoun in language processing
}

\author{
Theresa Redl ${ }^{1,2 *}$, Stefan L. Frank ${ }^{2}$, Peter de Swart ${ }^{2}, \&$ Helen de Hoop ${ }^{2}$ \\ ${ }^{1}$ Max Planck Institute for Psycholinguistics, Nijmegen, The Netherlands \\ ${ }^{2}$ Centre for Language Studies, Radboud University, Nijmegen, The Netherlands \\ *corresponding author: $\quad$ T.Redl@let.ru.nl
}

\section{Data:}

The data are openly available at https://osf.io/yqgav/. The doi is 10.17605/OSF.IO/YQGAV.

\begin{abstract}
A self-paced reading experiment tested if a generically-used masculine personal pronoun leads to a male bias in online processing. We presented Dutch native speakers ( $N=95,47$ male) with generic statements featuring the masculine pronoun hij 'he' (e.g., Someone who always promises that he will really be on time, such as $\mathrm{Ms} / \mathrm{Mr}$ Knoop, will sometimes be late anyway). We further presented participants with control items expressing the same meaning, but without the pronoun. Reading times were significantly higher when a female individual was given as an example (i.e., Ms Knoop in the example above) following the masculine generic pronoun $h i j$ ' he', but not in the control condition. This effect did not interact with participant gender. This shows that the generically-intended masculine personal pronoun leads to a male bias in online processing for male as well as female participants. Masculine personal pronouns are still commonly used for generic reference in many languages such as Dutch, but the results of this experiment refute the notion that a pronoun such as hij 'he' can be readily processed as gender-neutral.
\end{abstract}

\section{Introduction}

Each person knows when his appearance is unattractive. Moulton, Robinson, and Elias (1978) have shown that when we ask someone to write a story about such a person, the main character is more likely to be described as male rather than female. When singular their or the pronoun combination his or her is used instead of his to refer back to the person, however, the written stories are more gender-balanced (Moulton et al. 1978). Similarly, Gastil (1990) found that when a person reads a sentence such as After a patient eats, he needs to rest, they self-report to imagine the patient to be male significantly more often than when singular they or the combination of he and she is used in the sentence. Moulton et al. and Gastil along with other researchers (e.g., Hamilton, 1991; Hyde, 1984; Switzer, 1990; Wilson, 1978) have thus shown that when the English pronouns he, him, and his are used as so-called masculine generics, that is, intended to refer to a person of any gender despite being grammatically masculine, 
language users often seem to interpret the pronoun as referring to males only. At least, this is visible in offline tasks such as story writing or the reporting of mental imagery.

However, we know comparably little about how masculine generic pronouns are processed online, even though a few early studies on masculine generic pronouns also collected response times. For example, MacKay and Fulkerson (1979) asked participants to listen to sentences featuring the masculine generic pronoun he or his (e.g., A bicyclist can bet that he is not safe from dogs) and then indicate as quickly as possible whether a presented sentence could refer to one or more women. If the pronoun is interpreted as intended, the expected answer would be yes. However, MacKay and Fulkerson found the sentences to be judged as being able to refer to one or more females only $13 \%$ of the time. The descriptive analysis of the response times further revealed that yes-responses took longer than noresponses. They also found that participants generally took longer to respond to sentences featuring a generic pronoun compared to control sentences (e.g., The old housekeeper cleaned her carpet before sunrise). They interpreted this as an indication that a reading including women is not readily available when a masculine generic pronoun is used. However, the difference in response time between experimental and control items could be due to a variety of reasons, as the sentences were highly dissimilar. Even more so, MacKay and Fulkerson did not subject these numbers to statistical testing due to the small number of yes-responses and it is therefore unclear if these findings generalize.

Criticism of generic he grew louder starting in the 1970s, and the studies cited above provided empirical evidence to substantiate the claim that the use of generic he can lead to a male bias, at least offline. Remarkably, Lakoff (1973), who was one of the early critics of a gender bias in the English language, stated that trying to change the pronoun usage of English speakers and replacing generic he would be futile. Time has proven that her prediction was wrong; the frequency in use of generic he has since decreased, while usage of the gender-neutral alternative singular they has increased (Baranowski 2002; Earp 2012; LaScotte 2016). More recent studies on generic pronouns have thus focused on singular they, but by comparing singular they to its predecessor of sort he, some conclusions regarding the processing of masculine generic pronouns can still be drawn. For example, Noll, Lowry, and Bryant (2018) employed a lexical decision task in which participants responded to female or male definitional gender nouns such as aunt or uncle after having read a sentence featuring either the masculine generic he or singular they (e.g., A speaker should avoid reading a prepared speech, even if he/they will be nervous and want to get the wording exactly right). They hypothesized that if masculine generic he causes a male bias, then responses to male definitional nouns should be faster after these sentences. Noll et al. found no evidence for a male bias induced by he in their first experiment, but when repeating the experiment fifteen years later, they did find a facilitation effect for male probes after sentences featuring generic he, hinting at a male bias. Thus, only one of the two experiments provides evidence of a male bias in online processing caused by a masculine generic pronoun, but these results can also be interpreted as suggesting that as the use of he as a masculine generic decreased, its male bias has increased. 
As opposed to English, there are languages in which masculine generic pronouns are still very commonly and frequently used, yet little is known about how they are processed. One such language is Dutch. In an attempt to better understand the effects of masculine generic pronouns on online processing, multiple experiments have previously investigated the possessive pronoun zijn 'his'. Redl, Eerland and Sanders (2018) conducted an eye-tracking experiment in which participants read sentences such as Iedereen was zijn tanden aan het poetsen 'Everyone was brushing his teeth'. The activities in which the group of people described by everyone engaged were varied between stereotypically male, female and neutral. An individual member of the group was later referred to by means of a proper name, identifying them as either female or male. The authors hypothesized that reading times on female proper names would increase, as participants were expected to have previously made a male gender inference based on the pronoun zijn 'his', which would then mismatch the individual's actual gender. However, Redl et al. (2018) found no such evidence of a male bias induced by the pronoun. Redl, Frank, De Swart and De Hoop (2020) then conceptually replicated this eye-tracking experiment and did find zijn 'his' to cause a male bias, however, only for male participants and in stereotypically neutral contexts. In a second experiment, Redl, Frank et al. (2020) used the same stimuli in a sentence evaluation task. Participants had to evaluate whether the continuation of the sentence, which identifies part of the group as female or male, was a good continuation to the first part of the sentence featuring the masculine generic pronoun. They did not find sentences referring to men to be a better match than sentences referring to women. In other words, no signs of a male bias were found using the sentence evaluation paradigm. Finally, Redl, Szuba, De Swart, Frank and De Hoop (2020) conducted an eye-tracking experiment in which they embedded generic zijn 'his' in truly generic contexts, rather than episodic ones (e.g., Iemand met een absoluut gehoor kan snel zijn instrument stemmen 'Someone with perfect pitch can tune his instrument quickly'). Here again, the authors found zijn 'his' to cause a male bias only under certain conditions: only male participants experienced a delay in processing, and only when the antecedent was conceptually singular (i.e., iemand 'someone' as opposed to iedereen 'everyone'). The evidence regarding the processing of the possessive pronoun zijn 'his' when used as a masculine generic is thus mixed; men were found to show signs of a male bias in processing in two out of four experiments, but women never did.

One reason for focusing on the possessive pronoun zijn 'his' instead of the personal pronoun hij 'he' in these experiments was the assumption that if we found a male bias with zijn 'his', we would almost certainly find it with hij 'he' as well. However, since the evidence for zijn 'his' was mixed, it was necessary to conduct another experiment investigating hij 'he' in order to establish if a male bias would be found for this type of masculine generic.

As noted above, masculine generic pronouns are still frequently used in Dutch (and also in other languages such as German and French, see Red1 2020, for an exemplary overview of languages making use of masculine generic pronouns). This use of masculine pronouns for generic reference is often also described as the norm. For example, the leading dictionary of the Dutch language Van Dale states that 
masculine pronouns are used for generic reference, but alternatively hij/zij 'he/she' or hij of zij 'he or she' can be chosen (2015 p. xxxvi). Similarly, the Dutch Language Union, a regulatory institution regarding the Dutch language, still advises on their website taaladvies.net ('languageadvice.net') to use masculine pronouns when a person's gender is not known or irrelevant. Pair forms are the recommended alternative (e.g., hij/zij 'he/she' instead of hij 'he'), but only 'if one wants to avoid the risk of a one-sided male interpretation or if one really wants to emphasize that male as well as female individuals are being referred to' ('Zijn / haar (de sollicitant) "His/her (the applicant)"” n.d., author's translation). We conducted another processing experiment in order to be able to evaluate such a recommendation and evaluate how large 'the risk of a one-sided male interpretation' when using a masculine generic pronoun is. We used sentences such as the following:

1. Iemand die steeds belooft dat hij echt op tijd zal komen, zoals mevrouw/meneer Knoop, zal alsnog soms te laat zijn.

'Someone who always promises that he will really be on time, such as Ms/Mr Knoop, will sometimes be late anyway.'

There is one important difference between hij 'he' and zijn 'his', or rather between personal and possessive pronouns in general, leading us to hypothesize that $h i j$ 'he' is more likely to lead to a male bias. This could then possibly be reflected in men's as well as women's processing of the masculine generic pronoun. The personal pronoun hij 'he' is an independent pronoun which always functions as the subject of the clause. By contrast, the possessive pronoun zijn 'his' always functions as a determiner, and is thus dependent on the head noun of that noun phrase. Whereas zijn 'his' refers to a male possessor, the head of the noun phrase (the possessee) can just as well refer to a female. Consider the sentence Hij gaat met zijn moeder op vakantie 'He is going on vacation with his mother'. Although the possessive pronoun zijn 'his' refers to the same male character as hij 'he', the noun phrase zijn moeder 'his mother' refers to a woman. This mismatch between the genders of the possessor and the possessee can even lead to an error in the use of the possessive pronoun. Slevc, Wardlow Lane, and Ferreira (2007) conducted a production experiment and found that speakers were three times more likely to produce the wrong gender on the possessive pronoun when the gender of the possessor and possessee within the noun phrase mismatched ( $5.1 \%$ errors like He gave her sister a present) than when the genders matched (1.7\% errors like She gave his sister a present). They also found the error rate to be independent of the lexical noun used as long as the gender of the referent was known. That is to say, the noun cousin, which can refer to either a male or female, would lead to the same amount of gender errors as sister when the context made it clear (by a picture of the cousin wearing a skirt) that cousin referred to a female individual. In the studies on the possessive pronoun zijn 'his' in Dutch (Redl et al. 2018; Redl, Frank, et al. 2020; Redl, Szuba, et al. 2020), the head noun never referred to a person, hence there was never a gender mismatch within the noun phrase. Still, the fact that this type of mismatch (as in zijn zus 
'his sister') is ubiquitous in everyday speech indicates that a masculine possessive pronoun, and as a consequence also its male referent, is less salient than (the male referent of) a masculine personal pronoun. The personal pronoun hij 'he', on the other hand, is syntactically independent, and always the subject of the clause. This means that the pronoun's referent - a male individual - is also more salient. We therefore deem it more likely that a gender inference would be made based on hij 'he' than on zijn 'his' and hypothesize that the male bias would not only be visible in the processing of our male, but also of our female participants. We conducted an online self-paced reading experiment to test this. If our hypothesis is confirmed, the risk of a one-sided interpretation of this masculine generic pronoun as the Dutch Language Union puts it - would then have to be considered high, and alternatives to masculine generic pronouns might have to be endorsed more strongly than just as a last resort, as is currently done by the Dutch Language Union ("Zijn / haar (de sollicitant) "His/her (the applicant)"” n.d.).

\section{Materials \& Method}

\section{Materials}

The experiment featured 48 experimental items in four conditions (i.e., twelve per condition). All experimental items were generic statements about a type of person for which one specific individual was given as an example. Each item could occur in the experimental condition, which featured the complementizer dat 'that' followed by the masculine generic pronoun hij 'he' and including a finite verb. An example is provided in (1) above. The control condition expressed the same meaning through a non-finite clause with an implicit subject, hence without the personal pronoun hij 'he:

\section{Iemand die steeds belooft echt op tijd te zullen komen, zoals mevrouw/meneer Knoop, zal alsnog} soms te laat zijn.

'Someone who always promises to really be on time, for example Ms/Mr Knoop, will sometimes be late anyway.'

The woman or man given as an example was introduced by zoals 'such as', zo ook 'also' or bijvoorbeeld 'for example'. This was done in order to break the repetitive pattern. We further made sure that the woman or man introduced by mevrouw/meneer 'Ms/Mr' would always be interpreted as the subject right away. That meant that no other persons were present in the sentence, neither explicitly nor implicitly. We further avoided constructions in which the noun phrase introduced by bijvoorbeeld 'for example' could be temporarily construed as a direct object upon reading bijvoorbeeld 'for example' (e.g., a sentence such as Iemand die altijd hoopt nuttig advies te kunnen geven, bijvoorbeeld ... 'Someone who hopes to always give useful advice, for example ...' would not have been included). We also designed the stimuli in such a way that they sounded equally natural in both the experimental and 
the control conditions. The last names we used were common last names in the Netherlands with a frequency of at least 1000 ('Nederlandse Familienamenbank "Dutch family name database"” n.d.). We chose 48 last names for the experimental items that could not be associated with female or male gender in any way (i.e., none of the following names would have been included: patronyms (e.g., Hendricks), role nouns (e.g., De Boer 'lit. the farmer'), lexically male nouns (e.g., Prins 'lit. prince'), names ending in -man (e.g., Bosman 'lit. forest man'), anything that could be associated with gender in any other way (e.g., Borst 'lit. breast' or Damen 'lit. ladies')). Furthermore, all chosen last names consisted of one word only.

We also made sure that the first part of the stimuli did not contain any gender information apart from the masculine generic pronoun, as this could affect reading times. This was tested by subjecting the stimuli to a pre-test. Twenty-eight Dutch native speakers (12 male) completed this online pre-test. They ranged in age from 18 to $25(M=19.9)$. They were all students recruited through the participant pool of ANONYMIZED and received credit for their participation. We pretested 150 possible items in the control condition. Only the first part of the stimulus up until the first comma in (2) was presented. In addition, 50 filler items were created, 25 of which were stereotypically female, the other 25 being stereotypically male. All items had to be rated on a 7-point scale, indicating whether the participant thought that the description better fitted a woman or a man. The scale ranged from man to woman for half of the participants and was reversed for the other half. The middle of the scale (i.e., 4) represented an equally good fit for men and women. Before calculating the average for each item, we converted the scores, so that 1 corresponded to a female interpretation for both lists. We then checked whether participants followed the instructions and filled in the stereotypically male and female fillers as expected. The average ratings per participant for female fillers ranged from 1.00 to $3.04(M=1.81, S D$ $=0.47)$, while for male fillers they ranged from 4.6 to $7.00(M=6.02, S D=0.54)$. This shows that all participants responded to the fillers as expected and no pre-test participant was excluded. The means for all 150 potential experimental items ranged from 2.89 to 5.32 . We selected 48 items with a mean close to 4 as well as items with a low standard deviation. The means of the 48 selected items ranged from 3.21 to $4.79(M=4.01, S D=0.42)$. All experimental items can be found in the Supplementary material.

We constructed 48 fillers in four categories for the self-paced reading experiment in order to distract from the purpose of the experiment. We included 12 fillers describing habits of individuals (e.g., Sanne gaat meestal voor de lunch naar de supermarket 'Sanne usually goes to the supermarket before lunch'), and another 12 fillers about individuals were episodic (e.g., Joey heeft de deadline voor de scriptie gisteren niet gehaald 'Joey did not make the deadline for his thesis yesterday'). The individuals were denoted by a first name (18) or last name (6), none of which was used in the experimental items. Half of the sentences were about women, the other half about men. The final 24 fillers were not about specific individuals and were generic statements, either following the format Without X you... (e.g., Zonder medewerkerspas mag je in sommige kantines niet lunchen 'Without an 
employee ID you are not allowed to have lunch in some cafeterias') or generic statements starting with an inanimate subject and giving information about it (Panna cotta is een Italiaans nagerecht en betekent letterlijk gekookte room 'Panna cotta is an Italian dessert and literally means cooked cream'). Furthermore, a quarter of all experimental and filler items was followed by a comprehension statement which had to be judged as correct or incorrect.

Four lists were created, so that each item would occur in each condition, but never for the same participant. These lists were pseudo-randomized using the program Mix (Van Casteren \& Davis 2006). The following constraints applied: a maximum of two consecutive experimental items and three consecutive filler items was allowed, and a comprehension statement was presented at least every six items, but never twice in a row.

\section{Participants}

A total of 96 Dutch native speakers (48 male) participated in the experiment. They ranged in age from 18 to $35(M=23.3)$. None of the participants reported to have dyslexia or a different reading impairment. They were recruited through the subject database of ANONYMIZED and received $€ 6$ for their participation. All participants provided informed consent. The research presented in this article was approved by the Ethics Assessment Committee Humanities of ANONYMIZED. Two exclusion criteria applied: participants who guessed the purpose of the experiment would be excluded, as well as participants responding incorrectly to more than $25 \%$ of the comprehension statements.

\section{Procedure}

The online experiment was implemented on Ibex Farm (Drummond 2013). Ibex Farm only uses JavaScript and HTML, thereby not requiring the additional installation of plugins on the participants' part. Participants were first provided with general information about the experiment as well as the research policies at ANONYMIZED and ANONYMIZED regarding the use and storage of data. All participants provided consent. They were asked several demographic questions, after which they received more detailed instructions. Participants were then presented with four practice items, two of which were followed by a comprehension statement. The instructions were repeated in an abbreviated version and the main part of the experiment ensued. Ibex Farm uses the moving window paradigm, meaning that each trial started with a series of underscores representing each word. By pressing the spacebar, the first word appeared; when pressing the spacebar again, the first word disappeared and the second appeared etc. Participants were asked to use their dominant hand for this. A break was scheduled halfway through the experiment. Participants could determine the length of the break themselves. They were asked to guess the goal of the experiment after the self-paced reading task. 


\section{Analysis}

One male participant had to be excluded, as he responded correctly to less than $75 \%$ of the comprehension statements. No participant guessed the purpose of the experiment. We analyzed the reading times on two regions, namely on the word mevrouw/meneer ' $\mathrm{Ms} / \mathrm{Mr}$ ' as well as on the last name following it, the latter region serving as a spillover region. We excluded datapoints with a reading time below $150 \mathrm{~ms}$. This led to the exclusion of $0.42 \%$ and $0.84 \%$ of all datapoints for the main and spillover region, respectively. We then plotted a histogram of the log-transformed reading times on each region to identify outliers in the right tail. Based on this, we excluded datapoints exceeding 6.8 on the logarithmic scale (approx. 900ms) for the main region of interest. This led to the exclusion of a further $0.18 \%$ of the data for this region. For the spillover region, we excluded datapoints exceeding 7 on the logarithmic scale (approx. $1100 \mathrm{~ms}$ ), leading to the exclusion of a further $0.2 \%$ of the data in the spillover region.

The data were pre-processed and analyzed in R ( $\mathrm{R}$ Core Team 2018). We fitted a linear mixed model to the log-transformed reading times on the main region of interest as well as on the spillover region using the lmer function from the lme4 package (Bates, Mächler, et al. 2015). We fitted three fixed effects and all interactions between them. The fixed effects were PARTICIPANT GENDER (female versus male), CONTINUATION (female versus male) and STIMULUS TYPE (control versus hij 'he'). We used sum contrasts, with the first level of each factor named above coded as $1 / 2$ and the second level coded as $-1 / 2$. We initially fitted the full random structure permitted by the design. Following Bates, Kliegl, Vasishth, and Baayen (2015), we suppressed the correlation parameters as a first step of simplification. We then checked for overparameterization using Principal Component Analysis from the RePsychLing package and removed components which explained little to no variation, starting with higher order terms. All models included random intercepts for participants and items. The random slope structure of the final models is reported below. $P$-values were obtained through the $l m e r T e s t$ package (Kuznetsova et al. 2017). We followed Benjamini and Hochberg (1995) and applied false discovery rate control in order to correct for multiple comparisons, as we analyzed two regions. Significant effects are reported below, but the estimates for all fixed effects can be found in the Supplementary material.

\section{Results}

\section{Main region of interest: mevrouw/meneer 'Ms/Mr'}

The final model included random slopes for CONTINUATION and STIMULUS TYPE per participant, as well as CONTINUATION, PARTICIPANT GENDER, STIMULUS TYPE, CONTINUATION*STIMULUS TYPE and CONTINUATION*PARTICIPANT GENDER per item. There was a significant interaction effect between CONTINUATION and STIMULUS TYPE $(\beta=-0.06, S E=0.02, t=3.00, p=0.004)$. As can be seen in Figure 1 , men as well as women showed a significant increase in reading time for the female continuation 
mevrouw 'Ms' in the experimental condition featuring the pronoun hij 'he', but not in the control condition.

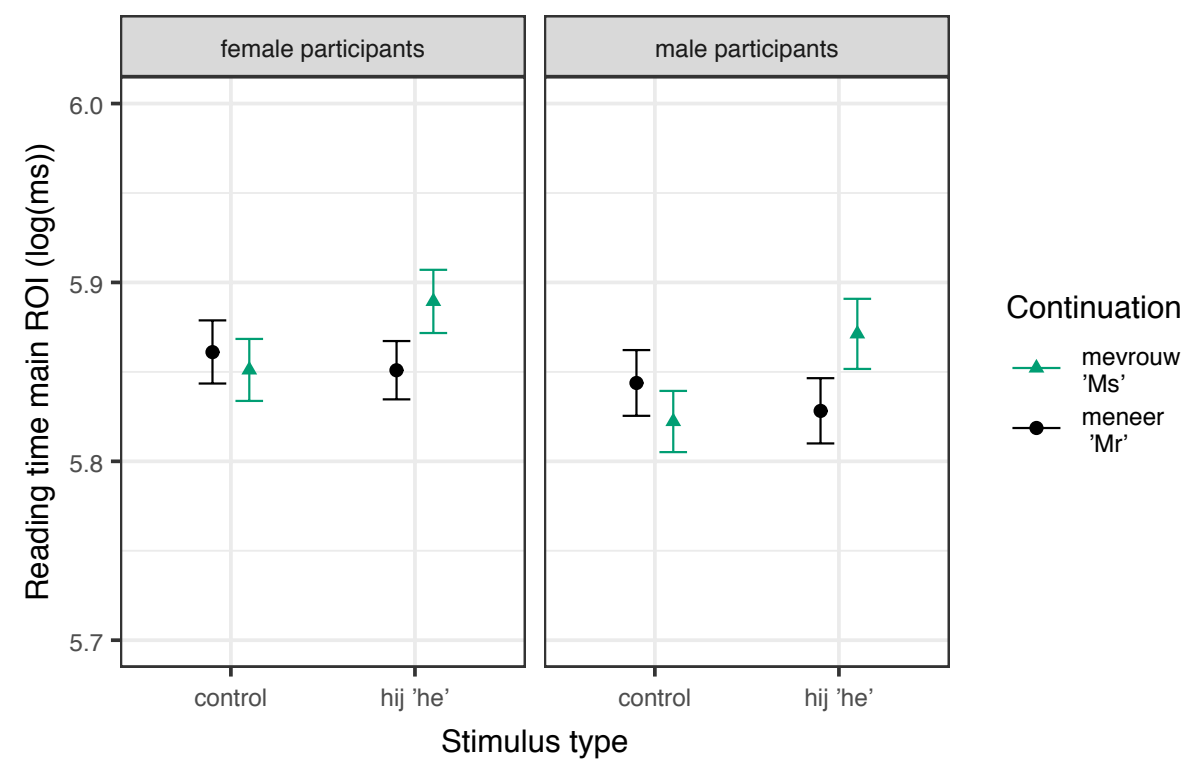

Figure 1. Mean reading times on the main region of interest mevrouw/meneer 'Ms/Mr' based on logtransformed data with $95 \%$ within-subject confidence intervals based on Morey (2008).

\section{Spillover region: last name}

The final model included random slopes for CONTINUATION per participant, as well as CONTINUATION, PARTICIPANT GENDER, STIMULUS TYPE, CONTINUATION*STIMULUS TYPE and CONTINUATION*PARTICIPANT GENDER per item. The interaction effect between CONTINUATION and STIMULUS TYPE was again significant $(\beta=-0.08, S E=0.02, t=3.58, p<0.001)$. As can be seen in Figure 2, the result pattern was similar to the main region of interest. 


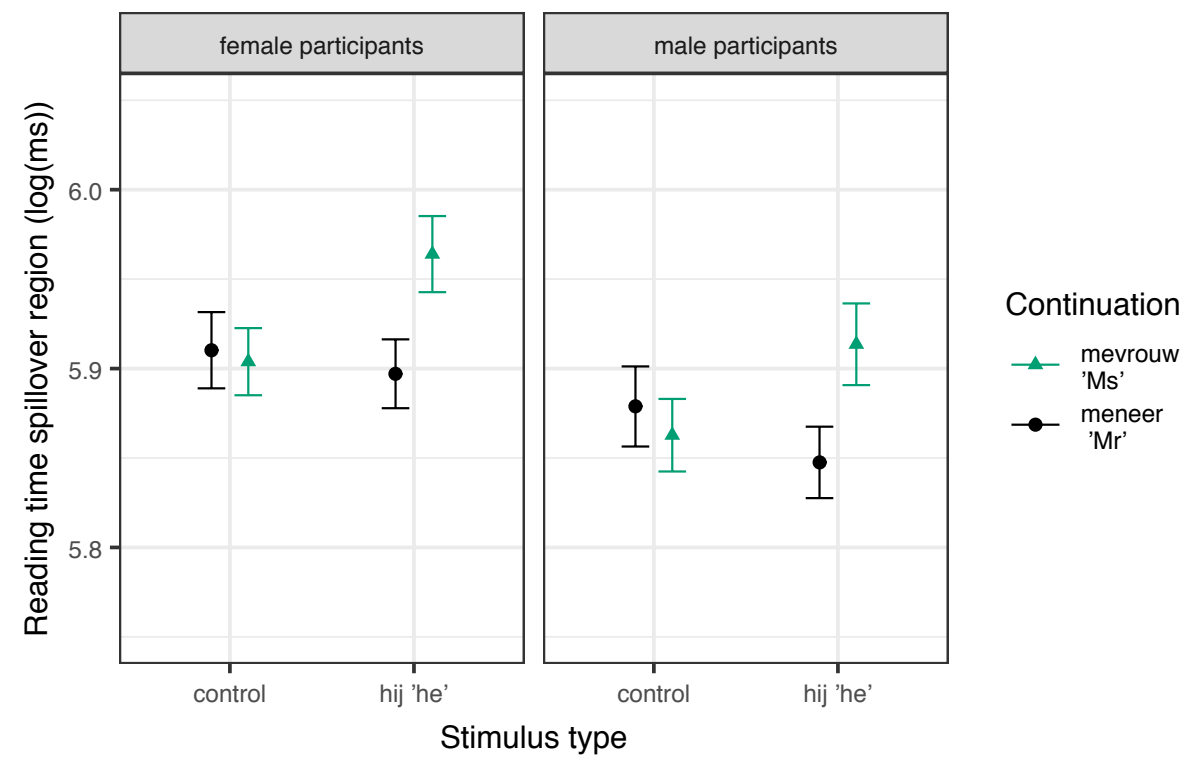

Figure 2. Mean reading times on the spillover region based on log-transformed data with $95 \%$ withinsubject confidence intervals based on Morey (2008).

\section{Discussion}

We conducted a self-paced reading experiment to investigate the effect of the masculine generic personal pronoun hij 'he' on language processing. To this end, we embedded the pronoun in a generic description of a person (e.g., Someone who always promises that he will really be on time) and then mentioned either a woman or man fitting that description by name (e.g., $M s / M r$ Knoop). The rationale was that if the pronoun triggers a gender inference despite being intended as generic, reading times for mentions of female individuals as an example would increase compared to mentions of male individuals. This is indeed what we found. Both male and female participants showed a significant increase in reading time on female continuations after the pronoun hij 'he' occurred, but not in the control condition, in which no pronoun was present. This is clear evidence of a male bias in language processing induced by the masculine generic pronoun hij 'he'.

As described in the Introduction, surprisingly little was known about the processing of masculine generic pronouns despite a long research tradition regarding gender bias in language, particularly in English. However, the pioneering studies on English masculine generic pronouns seldomly used online tasks. Newer studies do not fill this gap either, since the research focus now is on singular they, as its use has vastly increased while generic he has lost in popularity (Baranowski 2002; Earp 2012; LaScotte 2016). One exception are the two experiments by Noll et al. (2018), which suggest that the use of generic he leads to a male bias nowadays; in an experiment conducted 15 years earlier, however, they found no evidence of a male bias. To our knowledge, the only other language in which the processing of masculine generic pronouns was directly investigated is Dutch. Several experiments have tested whether the possessive pronoun zijn 'his' leads to a male bias when used generically, with mixed results. Two out of four experiments found evidence of a male bias, but in both cases for male participants only 
(Redl et al. 2018; Redl, Frank, et al. 2020; Redl, Szuba, et al. 2020). What has become clear from our experiment is that the Dutch personal pronoun hij 'he' leads to a male bias in online processing for both male and female participants, despite $h i j$ 'he' being frequently used as a generic. Thus, while the results obtained by Noll et al. suggest that he might not have led to a male bias when the generic reading was still highly frequent in English, we do not find this to be true for the Dutch equivalent hij. Despite hij 'he' still being frequently used generically, this reading is not readily available in online processing. Our results clearly suggest that language users make a gender inference based on the masculine generic pronoun during processing, even though the masculine gender is not intended as an indication of the referent's actual gender. It then takes additional time to accommodate the mental representation to include a female referent.

The masculine possessive pronoun zijn 'his' has previously only been found to lead to a male bias for male participants (Redl, Frank, et al. 2020; Redl, Szuba, et al. 2020). In this study, we did not find the genders to differ when it comes to the processing of hij 'he'. The gender difference found for zijn 'his' is in line with several offline studies on English masculine generic pronouns, of which many have found the genders to differ. More specifically, when an overall male bias was found, this bias was often larger for male participants (e.g., Gastil, 1990; Hamilton, 1988; Moulton et al., 1978; Switzer, 1990; Wilson, 1978). Several possible explanations have been put forward for this phenomenon. For example, Henley and Abueg (2003) suggest that this difference is rooted in language acquisition. Girls simply have to learn from a young age that masculine word forms can also be used to refer to them and they are therefore better at processing them this way. Alternatively, it has been suggested that language users project their own gender onto a mentioned person with unspecified gender (Hamilton 1988; Silveira 1980). Women would then mentally represent such a person as female, while men would resort to a male gender representation. However, this should then also be visible at least to some extent when no masculine generic pronoun is presented, such as in our control condition. This was not the case. Whatever the underlying mechanism for the previously found gender differences may be, our results suggest that it does not prevent the surfacing of a male bias when it comes to hij 'he' as opposed to zijn 'his'. As outlined in the Introduction, we believe a male referent of the personal pronoun hij 'he' to be more salient than a male referent of the possessive pronoun zijn 'his' due to the structural difference between personal and possessive pronouns. Our results suggest that this leads to a stronger male bias for hij 'he' than zijn 'his', which then in turn surfaces for men as well as women.

Furthermore, our current results underpin the validity of the eye-tracking experiment described by Redl, Szuba et al. (2020). They had found a male bias to arise for male participants when presented with generic statements such as Iemand met een absoluut gehoor kan snel zijn instrument stemmen 'Someone with perfect pitch can tune his instrument quickly'. They did not find a male bias in their control condition, for example Mensen met een absoluut gehoor kunnen snel hun instrument stemmen 'People with perfect pitch can tune their instrument quickly'. However, the authors could not exclude the possibility that the male bias in the experimental condition was actually due to a more general male 
bias and not due to the pronoun. It was theoretically feasible that a prototypical person introduced by someone would be represented as male regardless of the masculine generic pronoun following it, which could have explained the results, as well (Hamilton 1991; Silveira 1980). However, the control items in the current experiment were similar generic statements featuring the indefinite pronoun iemand 'someone' and no pronoun, and we did not find our results to be compatible with the idea of such a more general male bias affecting language processing. This suggests that the male bias shown by male participants in Redl, Szuba et al. was truly due to the presence of the masculine generic pronoun zijn 'his', and constitutes further evidence showing that masculine generic pronouns can cause a male bias even when there is no specific referent for the pronoun to refer to.

To conclude, our results show that masculine personal pronouns do not lend themselves for a gender-neutral reading. Even women, who have previously been shown to be able to access the generic reading of a masculine possessive pronoun during processing, clearly experienced a male bias in the current experiment. The use of alternatives to masculine generic pronouns is currently only endorsed to a limited extent in Dutch. These very alternatives, such as the pair form hij of zij 'he or she' or simply avoiding the pronouns altogether as we did in our control items, could eliminate this male bias. 


\section{References}

'Zijn / haar (de sollicitant) "His/her (the applicant)"'. (n.d.). Nederlandse Taalunie 'Dutch Language Union'.

Baranowski, M. (2002). 'Current usage of the epicene pronoun in written English', Journal of Sociolinguistics, 6/3: 378-97. DOI: 10.1111/1467-9481.00193

Bates, D. M., Kliegl, R., Vasishth, S., \& Baayen, H. (2015). 'Parsimonious mixed models', arXiv preprint arXiv: 1506.04967, 1-27.

Bates, D. M., Mächler, M., Bolker, B., \& Walker, S. (2015). 'Fitting linear mixed-effects models using lme4', Journal of Statistical Software, 67/1: 1-48. DOI: 10.18637/jss.v067.i01

Benjamini, Y., \& Hochberg, Y. (1995). 'Controlling the false discovery rate: A practical and powerful approach to multiple testing', Journal of the Royal Statistical Society: Series B, 57/1: 289-300.

Van Casteren, M., \& Davis, M. H. (2006). 'Mix, a program for pseudorandomization', Behavior Research Methods, 38/4: 584-9. DOI: 10.3758/BF03193889

Van Dale. (2015). Groot woordenboek van de Nederlandse taal., 15th ed. Utrecht \& Antwerpen: Van Dale publishers. DOI: 10.1080/19306962.1951.11786557

Drummond, A. (2013). 'Ibex Farm'.

Earp, B. D. (2012). 'The extinction of masculine generics', Journal for Communication and Culture, 2/1: 4-19.

Gastil, J. (1990). 'Generic pronouns and sexist language: The oxymoronic character of masculine generics', Sex Roles, 23/11-12: 629-43. DOI: 10.1007/BF00289252

Hamilton, M. C. (1988). 'Using masculine generics: Does generic He increase male bias in the user's imagery?', Sex Roles, 19/11-12: 785-99. DOI: 10.1007/BF00288993

- (1991). 'Masculine bias in the attribution of personhood: People $=$ Male, Male $=$ People', Psychology of Women Quarterly, 15/3: 393-402. DOI: 10.1111/j.1471-6402.1991.tb00415.x

Henley, N. M., \& Abueg, J. (2003). 'A review and synthesis of research on comprehension of the masculine as a generic form in English', Estudios de Sociolingüistica, 4/2: 427-54.

Hyde, J. S. (1984). 'Children's understanding of sexist language', Developmental Psychology, 20/4: 697-706. DOI: 10.1037/0012-1649.20.4.697

Kuznetsova, A., Brockhoff, P. B., \& Christensen, R. H. B. (2017). 'ImerTest Package: Tests in Linear Mixed Effects Models', Journal of Statistical Software, 82/13: 1-26. DOI: 10.18637/jss.v082.i13

Lakoff, R. (1973). 'Language and woman's place', Language in Society, 2/1: 45-80. DOI: $10.1017 / \mathrm{S} 0047404500000051$

LaScotte, D. K. (2016). 'Singular they: An empirical study of generic pronoun use', American Speech, 91/1: 62-80. DOI: 10.1215/00031283-3509469

MacKay, D. G., \& Fulkerson, D. C. (1979). 'On the comprehension and production of pronouns', Journal of Verbal Learning and Verbal Behavior, 18/6: 661-73. DOI: 10.1016/S0022- 
5371(79)90369-4

Morey, R. D. (2008). 'Confidence Intervals from Normalized Data: A correction to Cousineau (2005)', Tutorials in Quantitative Methods for Psychology, 4/2: 61-4. DOI: 10.20982/tqmp.04.2.p061

Moulton, J., Robinson, G. M., \& Elias, C. (1978). 'Sex bias in language use: "Neutral” pronouns that aren't', American Psychologist, 33/11: 1032-6. DOI: 10.1037/0003-066X.33.11.1032

'Nederlandse Familienamenbank "Dutch family name database". (n.d.). .

Noll, J., Lowry, M., \& Bryant, J. (2018). 'Changes over time in the comprehension of he and they as epicene pronouns', Journal of Psycholinguistic Research. Springer US. DOI: 10.1007/s10936018-9577-4

R Core Team. (2018). 'R: A Language and Environment for Statistical Computing. R Foundation for Statistical Computing'. Vienna, Austria.

Redl, T. (2020). Masculine generic pronouns: Investigating the processing of an unintended gender cue [Unpublished doctoral dissertation]. Radboud University.

Redl, T., Eerland, A., \& Sanders, T. J. M. (2018). 'The processing of the Dutch masculine generic zijn “his" across stereotype contexts: An eye-tracking study', PLOS ONE, 13/10: e0205903. DOI: 10.1371/journal.pone.0205903

Redl, T., Frank, S. L., De Swart, P., \& De Hoop, H. (2020). 'The male bias of a masculine generic pronoun: Evidence from eye-tracking and sentence evaluation', PsyArXiv. DOI: 10.31234/osf.io/84sf7

Redl, T., Szuba, A., De Swart, P., Frank, S. L., \& De Hoop, H. (2020). 'Masculine generic pronouns as a gender cue in generic statements [Manuscript submitted for publication]',.

Silveira, J. (1980). 'Generic masculine words and thinking', Women's Studies International Quarterly, 3/2-3: 165-78. DOI: 10.1016/S0148-0685(80)92113-2

Slevc, L. R., Wardlow Lane, L., \& Ferreira, V. S. (2007). 'Pronoun production: Word or world knowledge?', MIT Working papers in Linguistics, 53: 191-203.

Switzer, J. Y. (1990). 'The impact of generic word choices: An empirical investigation of age- and sexrelated differences', Sex Roles, 22/1/2: 69-82. DOI: 10.1007/BF00288155

Wilson, L. C. (1978). 'Teachers' inclusion of males and females in generic nouns', Research in the Teaching of English, 12/2: 155-61. 


\section{Acknowledgements}

We would like to thank Maria van de Groep and Joske Piepers for their help with the stimuli. We are also indebted to Noëlle Sommer for her help with implementing the experiment. 